\title{
Commentary Diabetes and sepsis outcomes - it is not all bad news
} Sachin Yende ${ }^{1,2}$ and Tom van der Poll ${ }^{3}$

\author{
${ }^{1}$ The Clinical Research, Investigation, and Systems Modeling of Acute Illness (CRISMA) Laboratory, University of Pittsburgh, Pittsburgh, PA 15261, \\ USA \\ 2Department of Critical Care Medicine, University of Pittsburgh, Pittsburgh, PA 15261, USA \\ ${ }^{3}$ Center of Infection and Immunity Amsterdam (CINIMA) and Center for Experimental and Molecular Medicine, Academic Medical Center, University of \\ Amsterdam, 1105 AZ Amsterdam, The Netherlands
}

Corresponding author: Sachin Yende, yendes@upmc.edu

Published: 18 February 2009

This article is online at http://ccforum.com/content/13/1/117

(C) 2009 BioMed Central Ltd

See related research by Esper et al., http://ccforum.com/content/13/1/R18
Critical Care 2009, 13:117 (doi:10.1186/cc7707)

survival [3]. These results would suggest that diabetes may have no effect or reduce mortality after infection. Indeed, results of epidemiologic studies to determine the effect of diabetes on short-term mortality after infection are conflicting [4-7].

The current study demonstrates complexities of understanding interaction between diabetes and outcomes of infection. Diabetes is a multifaceted disease and abnormalities include immune dysfunction and metabolic derangements, including hyperglycemia. Furthermore, these patients often have a higher burden of chronic conditions, such as cardiovascular and chronic kidney disease [8], and therapies used in diabetics, such as insulin, statins and thiazolidinediones, together with diabetes associated immune abnormalities $[9,10]$, may influence the host response to infection and outcomes. A clear answer to which factors influence the overall impact of diabetes on sepsis outcomes will require a translational approach using epidemiologic studies combined with animal and in vitro models.

The authors address most limitations in the current study. First, lower risk of acute respiratory failure could be confounded by lower risk of developing respiratory tract infection in diabetes, but subgroup analysis in individuals with a respiratory source of infection confirmed findings observed in the overall analysis. Second, the study used an administrative dataset and whether acute respiratory failure was due to acute lung injury could not be determined. Misclassification errors due to inclusion of patients with acute respiratory failure due to congestive heart failure or patients who were intubated due to septic shock without evidence of lung abnormalities may have occurred. Congestive heart failure is likely to be more common in diabetes and would attenuate the difference in the risk of acute lung injury between those with and without diabetes. Finally, administrative datasets and 
even well designed observational studies cannot tease out acute and chronic organ dysfunction. For instance, the diagnosis of acute kidney injury is difficult when pre-illness creatinine levels are not routinely available. Thus, the higher risk of acute kidney injury in diabetes could be confounded by higher prevalence of chronic kidney disease. Finally, discrimination between insulin-dependent and non-insulindependent diabetes could not be made, and no information was available on glucose levels at and after admission or on the regulation of diabetes prior to the septic episode (for example, by using $\mathrm{HbA} 1 \mathrm{c}$ levels).

In summary, these findings by Esper and colleagues advance our current understanding of the interaction between diabetes and infection. Well designed epidemiologic studies and translational approaches are necessary to understand the factors that contribute to sepsis outcomes in diabetics and the mechanisms involved. Unlike most non-infectious illnesses, such as cardiovascular disease and cancer, where diabetes is associated with poor outcomes [11,12], diabetes may confer some protection against acute lung injury in patients with sepsis and may not be associated with higher short-term mortality after infection - indeed it is not all bad news.

\section{Competing interests}

The authors declare that they have no competing interests.

\section{Acknowledgements}

Sachin Yende is supported by a K23 grant (K23GM083215) from the National Institute of General Medical Sciences, National Institute of Health.

\section{References}

1. Esper AM, Moss M, Martin GS: The effect of diabetes mellitus on organ dysfunction with sepsis: an epidemiologic study. Crit Care 2009, 13:R18.

2. Moss M, Guidot DM, Steinberg KP, Duhon GF, Treece P, Wolken $\mathrm{R}$, Hudson LD, Parsons PE: Diabetic patients have a decreased incidence of acute respiratory distress syndrome. Crit Care Med 2000, 28:2187-2192.

3. Rubenfeld GD, Caldwell E, Peabody E, Weaver J, Martin DP, Neff $M$, Stern EJ, Hudson LD: Incidence and outcomes of acute lung injury. N Engl J Med 2005, 353:1685-1693.

4. Falguera M, Pifarre R, Martin A, Sheikh A, Moreno A: Etiology and outcome of community-acquired pneumonia in patients with diabetes mellitus. Chest 2005, 128:3233-3239.

5. Kornum JB, Thomsen RW, Riis A, Lervang HH, Schonheyder HC, Sorensen HT: Type 2 diabetes and pneumonia outcomes: a population-based cohort study. Diabetes Care 2007, 30:22512257.

6. Benfield T, Jensen JS, Nordestgaard BG: Influence of diabetes and hyperglycaemia on infectious disease hospitalisation and outcome. Diabetologia 2007, 50:549-554.

7. Valdez R, Narayan KM, Geiss LS, Engelgau MM: Impact of diabetes mellitus on mortality associated with pneumonia and influenza among non-Hispanic black and white US adults. $\mathrm{Am}$ J Pub Health 1999, 89:1715-1721.

8. Prevalence of self-reported cardiovascular disease among persons aged $>35$ years with diabetes - United States, 19972005. MMWR 2007, 56:1129-1132.

9. Krogh-Madsen R, Moller K, Dela F, Kronborg G, Jauffred S, Pedersen BK: Effect of hyperglycemia and hyperinsulinemia on the response of IL-6, TNF- $\alpha$, and FFAs to low-dose endotoxemia in humans. Am J Physiol Endocrinol Metab 2004, 286:E766E772.
10. Stegenga ME, van der Crabben SN, Blumer RME, Levi M, Meijers JCM, Serlie MJ, Tanck MWT, Sauerwein HP, van der Poll T: Hyperglycemia enhances coagulation and reduces neutrophil degranulation, whereas hyperinsulinemia inhibits fibrinolysis during human endotoxemia. Blood 2008, 112:82-89.

11. Megherbi SE, Milan C, Minier D, Couvreur G, Osseby GV, Tilling K, Di Carlo A, Inzitari D, Wolfe CDA, Moreau T, Giroud M: Association between diabetes and stroke subtype on survival and functional outcome 3 months after stroke: data from the European BIOMED stroke project. Stroke 2003, 34:688-694.

12. Abbott RD, Donahue RP, Kannel WB, Wilson PW: The impact of diabetes on survival following myocardial infarction in men vs women. The Framingham Study. JAMA 1988, 260:3456-3460. 